\title{
Ethics and refinement in animal research
}

Olsson, I. Anna S.; Hansen, Axel Jacob Kornerup; Sandøe, Peter

Published in:

Science

DOI:

10.1126/science.317.5845.1680

Publication date:

2007

Document version

Publisher's PDF, also known as Version of record

Citation for published version (APA):

Olsson, I. A. S., Hansen, A. J. K., \& Sandøe, P. (2007). Ethics and refinement in animal research. Science, 317(5845), 1680. https://doi.org/10.1126/science.317.5845.1680 


\title{
Ethics and refinement in animal research ${ }^{1}$
}

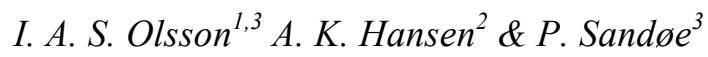

${ }^{1}$ Laboratory Animal Science, IBMC - Instituto de Biologia Molecular e Celular, Universidade do Porto, Portugal

${ }^{2}$ Division of Laboratory Animal Science and Welfare, Faculty of Life Sciences, University of Copenhagen, Denmark

${ }^{3}$ Danish Centre for Bioethics and Risk Assessment, Faculty of Life Sciences, University of Copenhagen, Denmark

Based on a case study we conclude that scientists and journals could and should do more to secure the ethical standards of animal use in biomedical research: Scientists often justify animal use referring to the scientific value and biomedical importance (2). However, except from a purely anthropocentric perspective, ethical concern about compromised animal welfare cannot be justified by human benefits alone (1). It is equally important that the benefits are achieved with a minimum of negative effects to the animals involved. Thus scientists must apply 'refinement', the third R of the so-called 3Rs (3). But here scientists seem sometimes to do less than they should and journals fail in their duty to enforce high ethical standards.

We studied the use of animals as models for the neurodegenerative Huntington's Disease. Here refinement should focus on limiting the negative impact of declining sensorimotor function as the disease progresses: housing adaptations facilitating food and water intake and humane endpoints (using earlier, less severe clinical signs as endpoint parameters rather than awaiting spontaneous death) are two possible approaches (4). We asked to what extent animal welfare problems and refinements addressing them were reported in publications of the most common rodent models by analyzing 90 research reports published in international peer-reviewed journals during 2003-2004. These include quinolinic acid (5,6) and 3-nitropropionic acid $(6,7)$ administration to rats and mice and R6/1, R6/2 and N171-82Q transgenic mice $(8,9,10)$. Our results show that the majority of experiments $(36+17)$ were in the two most severe categories, in which animals have sensorimotor deficits interfering with their capacity to eat and drink normally from the cage top $(11,12,13)$.

\footnotetext{
${ }^{1}$ The reference of the printed version is:

I. Anna S. Olsson, Axel Kornerup Hansen \& Peter Sandøe (2007): Ethics and Refinement in Animal Research (letter).

Science 317: 1680.

The definitive version is available at

http://www.sciencemag.org/cgi/content/citation/317/5845/1680
} 
Very few papers reporting such severe experiments included information on refinement measures: Out of 14 survival studies of transgenic animals with a progressive neurodegenerative phenotype, only 6 referred to humane endpoints and only 2 to housing adaptations. Among the majority of studies referring to compliance with official regulations and / or efforts to reduce animal suffering, we also found experiments using far from best practice, such as administration of rising neurotoxin doses until high animal mortalities.

We believe that our study permits two main conclusions about the role of scientific journals in enhancing the ethical standards of research with animals. First, journals should ensure that referees seriously consider whether submitted studies were indeed carried out with the smallest achievable negative impact on the animals. Although important results might be found in a paper not complying with current refinement standards, a journal like Science should still reject such a paper, thereby sending an important signal to the research community, similar to what is common practice for studies involving human research subjects. Secondly, journals should give authors space to describe refinement and welfare precautions. We demonstrate that such descriptions are rare, which means that other researchers cannot benefit from refinement ideas (14), in turn implying a real danger that animals will have to suffer unnecessarily, and that animal welfare will be improved later than necessary.

\section{References}

1. I. A. S. Olsson, P. Robinson, K. Pritchett, P. Sandøe, in Handbook of Laboratory Animal Science, G. Van Hoosier, J. Hau, Eds (CRC Press, Boca Ratoon, ed. 2, 2002), pp13-30.

2. E. Frankel Paul, J. Paul, Eds Why Animal Experimentation Matters: The Use of Animals in Medical Research Transaction Publishers, New Brunswick, 2000).

3. W. M. S. Russell, R. L. Burch. The Principles of Humane Experimental Technique 1959/1992, http://altweb.jhsph.edu/publications/humane exp/foreword.htm.

4. D.B. Morton, J. Hau, in Handbook of Laboratory Animal Science, G. Van Hoosier, J. Hau, Eds (CRC Press, Boca Ratoon, ed. 2, 2002), pp 457-486.

5. M.F. Beal et al., Nature 321, 168-171 (1986).

6. E. Brouillet, F. Condé, M.F. Beal, P. Hantraye, Prog. Neurobiol. (Oxf.) 59, 427-466 (1999).

7. E. Brouillet et al., J. Neurochem. 60, 356-359 (1993).

8. L. Mangiarini et al., Cell 87, 493-506 (1996). 
9. E. Hockly, B. Woodman, A. Mahal, C. M. Lewis, G. Bates, Brain Res. Bull. 61, 469-479 (2003).

10. G. Schilling et al., Hum. Mol. Genet. 8, 397-407 (1999).

11. Home Office. Guidance on the Operation of the Animals (Scientific Procedures) Act 1986.

http://www.archive.official-documents.co.uk/document/hoc/321/321-05.htm\#gen114 (2000).

12. J. Richmond, personal communication

13. Canadian Council on Animal Care. Categories of Invasiveness in Animal Experiments.

http://www.ccac.ca/en/CCAC Programs/Guidelines_Policies/POLICIES/CATEG.HTM (1991).

14. H. Würbel, Nature 445, 357 (2007).

15. The authors wish to thank colleagues in the COST Action B24 Laboratory Animal Science and Welfare; researchers Nico Dantuna, Christa Maynard, Christoph Kosinski, Elsa Diguet, Dwaine Emerich and Hoa Huu Phuc Nguyen, who provided information on clinical signs in different models; and Paul Robinson, who commented on a previous version of the paper. Preparation of this paper was part of the interdisciplinary project Comparative Genomics of Man and Pig, funded by the Danish Agency for Science, Technology and Innovation. The authors declare no competing financial interests. 